\title{
Inherent safety concepts in nuclear power reactors
}

\author{
OM PAL SINGH and R SHANKAR SINGH
}

Reactor Physics Division, Indira Gandhi Centre for Atomic Research, Kalpakkam 603 102, India

MS received 6 September 1988; revised 27 January 1989

\begin{abstract}
Different inherent safety concepts being considered in fast and thermal reactors are presented after outlining the basic goals of nuclear reactor safety, the 'defence in depth' philosophy to achieve these goals and the characteristics affecting the safety of liquid metal fast breeder and light water reactors. The inherent safety potential of fast reactors with respect to different sizes and types of fuel is also discussed. Finally, the approach proposed for the Indian Prototype Fast Breeder Reactor (PFBR), which is in the detailed design stage, is also presented.
\end{abstract}

Keywords. Liquid metal fast breeder reactor; light water reactor; inherent safety; engineered safeguards; PIUS, HTG, PRISM and SAF reactors.

\section{Introduction}

In a nuclear power reactor, energy is produced through a nuclear fission reaction, in which a large number of fission products are also produced. These fission products are radioactive and, therefore, a large nuclear reactor contains gigacuries of radioactivity in the fuel during its normal operation. Any accidental release of it to the atmosphere can lead to a major disaster. Therefore, the basic goals of nuclear reactor safety are:

(i) release of radioactivity from the reactor to the environment affecting the general public should be kept well below permissible levels;

(ii) the probability of any serious accident that could result in severe damage to the reactor should be reduced to the extreme minimum.

To achieve these goals, safety is provided at three levels in nuclear reactors.

At the first level, the basic thrust is to incorporate inherent safety into the system through suitable reactor physics parameters and quality assurance of a high level in all the phases of design, construction and operation of the reactor. Here, the basic aim is to make the probability of accident/fault initiation as low as possible. If the fault/accident is initiated inspite of the measures taken at the first level of safety, then one would like to shut down the reactor and make suitable arrangements for the subsequent removal of fission product decay heat. Therefore, at the second level, a highly reliable Plant Protection System (PPS) is provided to handle a wide range of 
conceivable abnormal incidents and malfunctions and safely shut down the plant. The PPS includes a variety of instruments and sensors to monitor the state of the plant and to take protective as well as sympathetic control action to prevent any abnormality leading to an accident. The third level of safety measures are addressed to those events, which although never expected to occur, are nevertheless mechanistically possible inspite of the first and second level safety measures. Such events result in severe core damage and hence reactor containment is provided to arrest the release of radioactivity to the atmosphere. Such accidents are labelled design basis accidents (DBA) and since the probability of such accidents is very very small, $<10^{-6}$ per reactor per year (Walter \& Reynolds 1981), these accidents are also called hypothetical core disruptive accidents (HCDA). Accidents with probability of occurrence in the range of $10^{-6}$ to $10^{-7}$ and $<10^{-7}$ per reactor per year are termed as BDBA (beyond basis accidents) and accidents in the residual risk respectively (Languille 1985).

The above approach provides a 'defence in depth' against accidents to nuclear reactors. A lot of emphasis has been laid on improving the reliability of measures applied at the second level using reliability principles like redundancy, diversity etc. However, since engineered safeguards like the PPS at the second level and containment at the third level of safety, always have some probability of failure - however small the probability may be - innovative approaches have been thought of to replace as much as possible, the engineered safeguards of second level safety by foolproof laws of physics and chemistry. That is, the idea is to shut down the reactor automatically and remove the subsequent decay heat by processes based on natural laws of physics and chemistry without invoking any engineering safeguard or human intervention. Reactors with such design features are called inherently safe reactors. In this paper, we discuss the various concepts being considered for making thermal and fast reactors inherently safe and also present some results of theoretical analysis and experiments in support of these concepts. The inherent safety potential of fast reactors with different types of fuel is also discussed. Finally, the approach proposed for the Indian PFBR is highlighted.

Before discussiong the inherent safety concepts being considered for fast reactors (liquid metal-cooled fast breeder reactors, LMFBR) and thermal reactors (light water reactors, LWR) comparative characteristics of LMFBR and LWR (Walter \& Reynolds 1981), which are important from the safety point of view, are discussed.

\section{Characteristics affecting safety of LMFBR and LWR}

\subsection{Core assembly}

In fast reactors, the reactor core is not in its most reactive configuration and hence a theoretical possibility exists that under certain conditions like core melting and compaction, the reactor core may acquire more reactive configuration leading to increase in power and more energy release than is removed from the reactor. In thermal reactors, the core is in optimal reactive geometry and hence any change in the core assembly configuration results in reactivity reduction. Therefore, in fast reactors, sufficient emphasis is placed on making PPS as reliable as possible so that the reactor is shut down before the change in core assembly takes place due to core melting. Core melting accidents resulting from mismatch in power produced in and power removed from the core are considered design basis accidents for LMFBR. 


\subsection{Stored energy in the coolant}

LMFBR operate at low ( $\sim 5 \mathrm{~atm}$ or $0.5 \mathrm{GPa})$ pressure and the LWR operate at high ( $\sim 70 \mathrm{~atm}$ for BWR and $\sim 150 \mathrm{~atm}$ for PWR) pressure. Therefore, unlike LMFBR, coolant depressurisation due to breach in the primary system would lead to coolant blow-down in LWR. This would lead to core damage and hence exposure of core fission products to the atmosphere. Coolant pipe-break is a DBA for LWR. Emergency core cooling systems (ECCS) are provided in LWR to cool the reactor core under such circumstances.

\subsection{Effect of loss of coolant on reactivity}

Loss of coolant in LWR results in a decrease in reactivity. In a small size LMFBR also, coolant loss results in reactivity decrease due to increase in neutron leakage. However, for large-sized LMFBR, coolant loss leads to gain in reactivity due to hardening of the neutron spectrum resulting in increased fast fission in fertile uranium and decreased capture of neutrons in fissile, fertile and structural material: the neutron leakage effect being relatively small. Therefore, for such LMFBR, special techniques are needed to detect coolant boiling in its incipient stage so that appropriate safety action could be taken in time.

\subsection{Inherent emergency decay heat removal capability}

LMFBR possess a higher capability for decay heat removal because of higher heat capacity of liquid sodium coolant and its better natural convection cooling capability as compared to LWR. Hence in LWR more emphasis is laid on reliable decay heat removal systems.

\subsection{Chemical energy}

In LMFBR, chemical reaction between sodium and water, sodium and concrete or sodium and air can lead to large energy release that may damage certain systems. At normal operating temperatures, such a possibility does not exist in LWR. However, at high temperatures, zirconium-steam reaction in LWR can lead to hazardous energy release. Suitable safety measures are taken to prevent or mitigate the consequence of such an eventuality in these reactors.

\subsection{Nuclear properties}

In fast reactors, both the kinetic parameters, $\beta$, the fraction of delayed neutrons, and $\Lambda$, the prompt neutron life time, are smaller than in the thermal reactors. Therefore, theoretically, super-prompt critical accidents are more serious in fast reactors than in the thermal reactors. However, in practice, due to large and prompt negative reactivity feedbacks in LMFBR, the system tends to remain in a sub-prompt critical state under reactivity transients and hence the power rise is slow and limited. Thus, the difference in $\beta$ and $\Lambda$ values of the fast and thermal reactors is not of any special consequence when the system is below prompt critical. 


\subsection{Radiological inventory}

In fast and thermal reactors of equivalent size, fission product inventory is of the same order in both types of reactors. However, plutonium inventory is larger in fast reactors. Therefore, fast reactor irradiated fuel requires special care in its transport and handling etc.

\subsection{Thermal time constant}

Thermal time constants for fast reactors are smaller than those in the normal reactors due to their smaller pin size and the better heat transport characteristics of the coolant. Therefore, fast reactors are relatively stable with respect to minor fluctuations in the reactivity of the system. The effect of time constants is properly evaluated by performing transient and dynamic studies.

\section{Inherent safety concepts in nuclear reactors}

From the above discussion it is clear that in fast reactors, the main concern is with incidents leading to core voidage and core melting. Therefore, in these reactors, inherent safety concepts should lead to automatic shut down of the reactor on initiation of events leading to core voidage and melting. The consequent decay heat must be removed by natural convection processes without any human intervention or taking recourse to engineering devices. In thermal reactors, the main concern is with coolant pipe break leading to coolant depressurisation and its blowdown. Hence inherent safety concepts in these reactors should eliminate the possibility of sudden depressurisation of the coolant and protection against inadvertent power rise should again be by passive means, while the removal of decay heat should be by natural convective processes.

The basic safety goal in nuclear reactors is protection against release of radioactive materials into the atmosphere under any credible incident, human etror or malicious intervention. The radioactive fission products in nuclear reactors have, by design, four barriers, namely fuel matrix, clad, primary system and containment, before they can get released to the atmosphere. In principle, if any one of them is intact, dispersal of radioactivity to the environment is avoided. However, since the failure of primary system is always probable and is taken as the initiating event for most of the safety analysis, and dependence on reactor containment is not fully reliable because it may remain open by human error or by malicious intervention, and also because it is too large to make it impenetrable by external attack, the only possibility for attaining the above safety goal is by retaining intact the two remaining barriers at any cost. That is, the fuel matrix and the cladding. So, more specifically, the goal of a inherently safe reactor is to preserve the fuel integrity under all conditions and without reliance on engineered safety or human intervention. Since fuel disintegration during reactor operation can only occur due to its overheating, inherent reactor safety could be achieved by keeping the core always submerged in the pool of coolant and ensuring, by providing suitable reactivity feedback mechanisms, that the rate of heat generation is always low enough to avoid overheating of the fuel pin. The inherent safety concepts in thermal and fast reactors have evolved based on the above requirements. 


\subsection{Thermal reactors}

At present there are two well thought out ideas for inherently safe thermal reactors (Weinberg \& Spiewak 1984), the Process Inherent Ultimately Safe (PIUS) reactor being developed in Sweden by ASEA/ATOM (Hannerz 1983, 1984, 1987) and High Temperature Gas (HTG) reactor proposed by General Atomics (GA) in USA (Fisher et al 1984) and by Interatom/KWU in Germany (Reutler \& Lohnert 1983). In addition, several other concepts have also been proposed but here we discuss only these two, the other concepts not being developed fully as yet.

3.1a The PIUS concept and SECURE-P reactors: ASEA/ATOM is currently working on three reactor designs using the PIUS-principle, SECURE-P for electric power production, SECURE-H and SECURE-LH for heat production at $150^{\circ} \mathrm{C}$ and $100^{\circ} \mathrm{C}$ respectively. The SECURE-P reactor is called the PIUS reactor in the USA. In the following, we discuss the PIUS principle and some of the design and analysis results of the SECURE-P reactor.

The PIUS-principle is based on the concept that the process of heat extraction from the core should be designed such that in all foreseeable incidents core integrity is guaranteed by the laws of gravity and thermohydraulics alone (Hannerz 1983). This is achieved by keeping the core and primary system submerged in a large pool of borated water at all times and avoiding a core power which exceeds the cooling capability of the submerged coolant.

The pool of water is contained at full reactor pressure within a large prestressed concrete reactor vessel (PCRV). The PCRV is made leak-proof by a stainless steel liner and a leak-tight barrier consisting of a mild steel membrane cast into the concrete away from the stainless steel liner. With such a configuration, it is impossible for any type of leak to take place, and the concrete vessel itself is so massive ( $7-10 \mathrm{~m}$ thick) that it can withstand extreme external pressure, including that of explosives. All penetrations into the reactor are from the top of the PCRV. Any external explosive can damage the piping and penetrations in the upper part of the vessel but will not lead to loss of the required water inventory from its lower part. For the core, sitting deep into the pool, there are no credible scenarios for loss of coolant water other than by evaporation. However, such a core is of no use unless a circuit is introduced to extract the useful heat from this. How this is achieved is most easily understod from figures 1a to 1d (Bredolt et al 1988; Hannerz 1987). Figure 1a indicates that a heat source (nuclear core) placed in a vertical pipe in a pool of water will cause an upward flow in the pipe. If the heated water is returned to the lower end of the pipe by means of a pump there would be no net flow from and to the pool (figure $1 \mathrm{~b}$ ). The heat generated can be extracted for a useful purpose by heat exchangers (figure 1c) and the mixing between hot circulated and cold pool water is prevented by stable stratification in tube bundles, known as density locks (figure Id). By placing the pool in a closed vessel and pressurising with a steam bubble above the circulation system, the latter can be operated at high pressure and temperature. By keeping the pump flow within a relatively narrow control range, determined by permissible level fluctuations in the density locks, the hot circulating coolant can be kept separated from the cold water with high boron concentration in the pool.

The principle of flow arrangement used in the PIUS reactor is depicted in figure 2. During normal operation, the hot primary cooling water is pumped through the core and the steam generators. The primary circuit is connected with the cold pool through pressure-balanced interfaces below the core and at the top of the vessel. If the core 

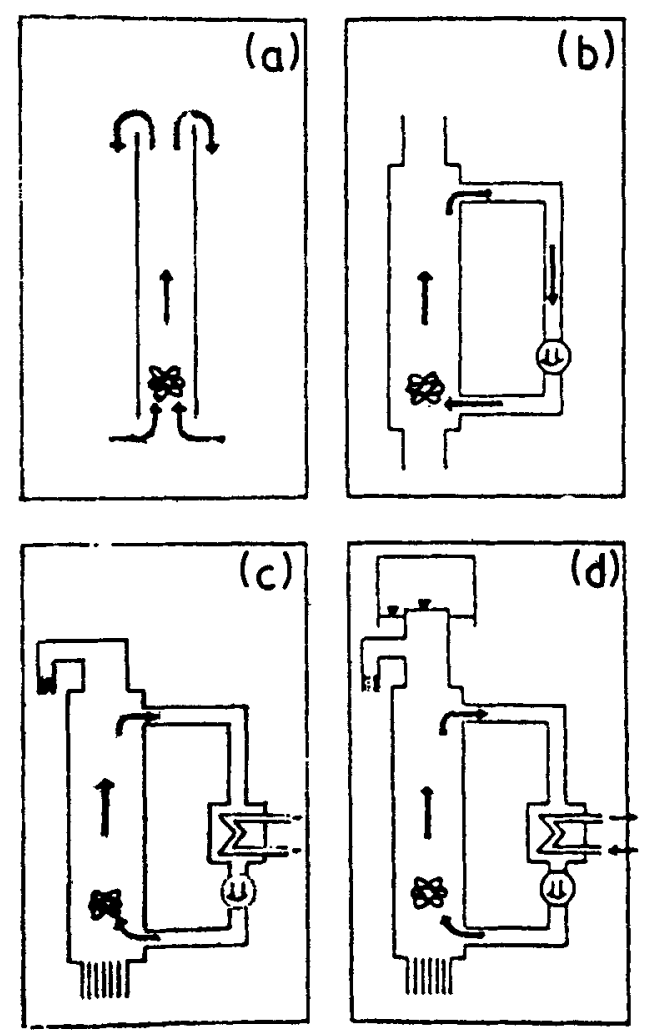

Figure 1. The operating principle of the Pius primary system. (a) Heat source (nuclear core) placed in a vertical pipe in a pool of water causes an upward flow in the pipe. (b) If heated water is returned to the lower end of the pipe, there is no net llow to and from the pipe. (c) Heat exchangers can be used to extract the heat. (d) Mixing between hot circulated and cold pool water is prevented by density locks.

power rises to a hazardous level, its coolant outlet temperature and the temperature in the riser chimney will increase. This results in sucking more water flow and the difference between this and the flow delivered by the pump is made up of inflow from the cold borated pool through the lower hot/cold interface opening. This leads to reduction of power to a safe level or to reactor shut down depending on the nature of the incident. This principle of ensuring ultimate safety relying on fluid properties and the design of the heat extraction process itself has been given the acronym, PIUS, for Process Inherent Ultimate Safety (Hannerz 1987). For decay heat removal, cooling is achieved by providing sufficient water in the pool so that its evaporation suffices for decay heat removal for the required period of time. A period of one week is considered sufficient for this purpose for the SECURE-P reactor.

SECURE-P (Hannerz 1984) is a $600 \mathrm{MWe}$ Pressurized Water Reactor (PWR) with a modular design, each module consisting of a core producing $200 \mathrm{MWe}(670 \mathrm{MWth})$ power, a steam generator and a pump. All the three modules are connected to one common turbine. The reactor core is made up of 89 open lattice PWR-type fuel assemblies with a $16 \times 16$ pin lattice. The active core height $(1.97 \mathrm{~m})$ is roughly half of the conventional PWR core so that the pressure drop across the core is well below the maximum tolerable limit for achieving the pIUs-type pressure balance based on density differences. The specific power is $60 \%$ of that of the PWR and hence the fuel is less subdivided and the fuel rod diameter is $12.3 \mathrm{~mm}$ as used for boiling water reactors (BWR). Average burn-up is expected to be $36 \mathrm{MWd} / \mathrm{kg}$. Fuel enrichment is $3.7 \%$. Reactivity compensation for burn-up is mainly with gadolinia absorbers. There are no control rods in the reactor. Reactivity is controlled by boron and temperature 


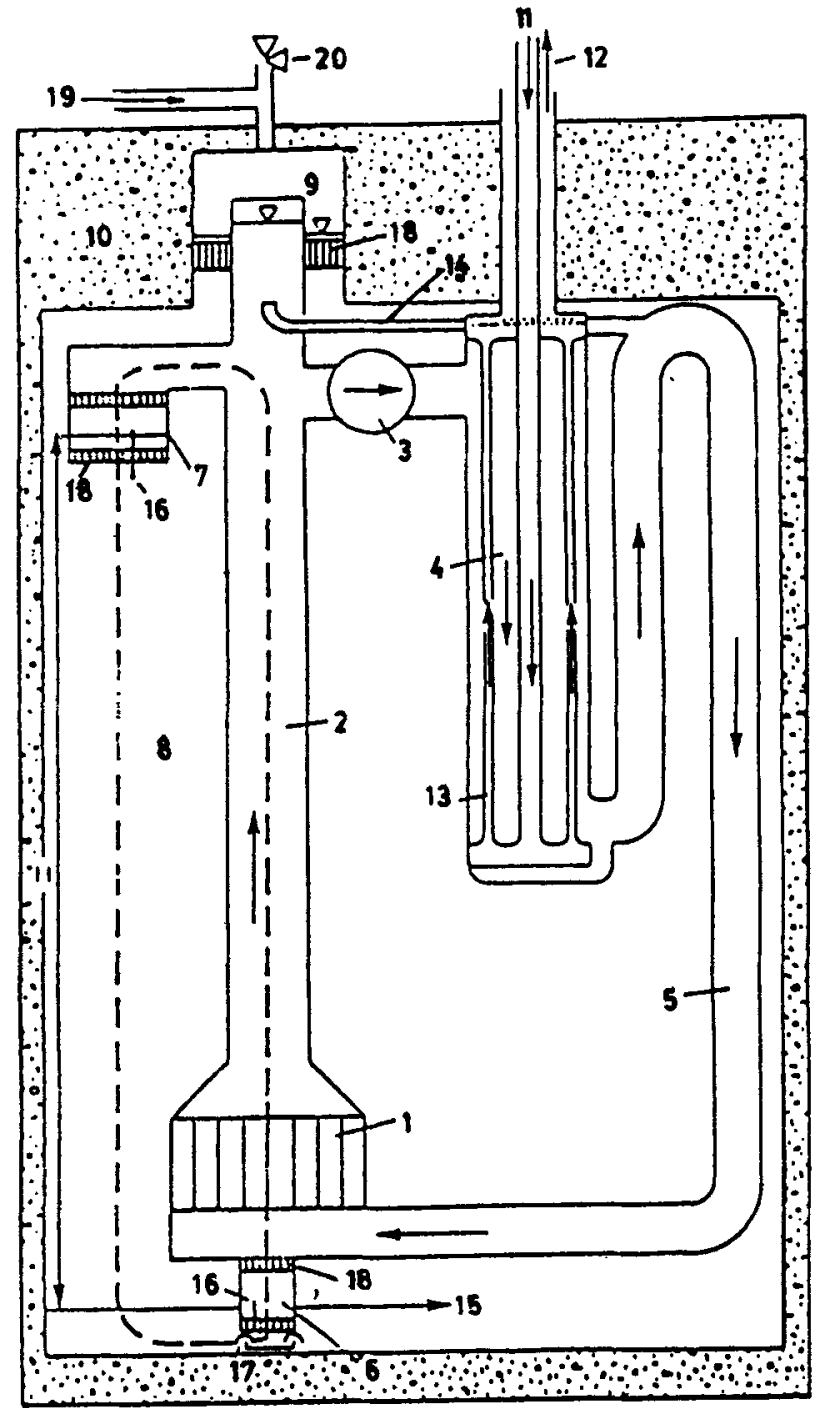

1. Core

2. Riser

3. Primary circulation pump

4. Once-through steam generator

5. Downcomer

6. Lower hot/cold interface

7. Upper hot/cold interface

8. Cold pool water

9. Steam volume of pressuriser

10. Prestressed-concrete pressure vessel

11. Feedwater to steam generator

12. Steam to turbine

13. Steam generator tubes

14. Syphon breaker pipe

15. Water to purification \& separation

16. Temperature sensors for locating hot/cold interface level

17. Gas lock arrangement

18. Honeycomb structure for preventing horizontal flow

19. From electrical boiler

20. Pressure relief valves

Figure 2. Principle of flow arrangement used in the PIUs reactor. The dotted line indicates the natural circulation circuit.

only. Fuel assemblies are provided with adjustable orifices at their inlet so that core pressure drop can be adjusted corresponding to the level difference between the upper and lower interfaces and the density difference in pool water. The thermal design provides adequate margins to departure from nuclear boiling. Spent fuel is stored in the PCRV. The modular design is chosen because a module can be fully shop-fabricated and operated independently and the primary system can be fully standardised. The modular design is possible only in PIUS concept reactors because in a conventional plant, each core needs its own safety system and hence their modular design would be highly uneconomical. The vertical cross-sections showing the general arrangement of the steam generating system of SECURE-P is shown in figure 3. The coolant outlet temperature is $291^{\circ} \mathrm{C}$. The coolant goes up straight through the $1.6 \mathrm{~m}$ dia and $20 \mathrm{~m}$ height riser pipe. The riser pipe branches off into two at the top. One of them 


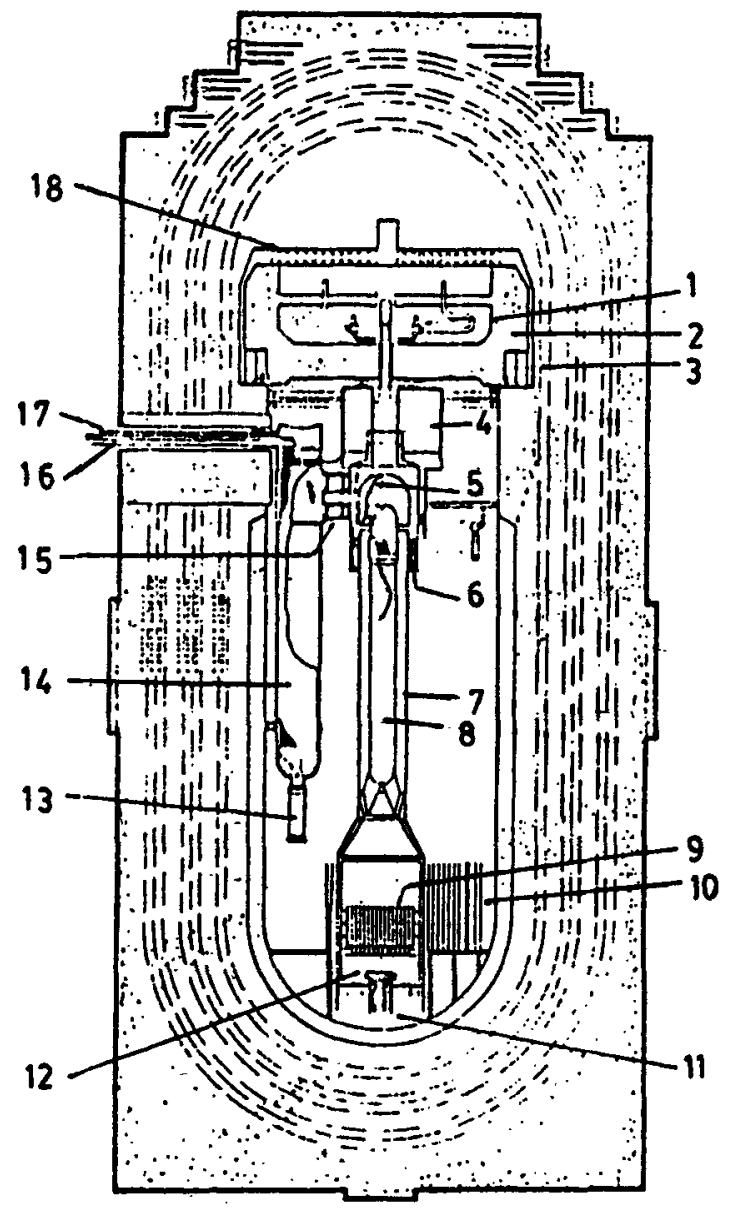
1. Steam relief valves
2. Vessel head
3. Pool coolers
4. Pressurizer with steam volume
5. Inlet to steam generator
6. Upper hot/cold interface region
7. Riser
8. Downcomer
9. Core
10. Spent fuel storage racks
11. Lower hot/cold interface region
12. Core inlet plenum
13. Recirculation pump motor
14. Steam generator
15. Outlet from steam generator
16. Feedwater line
17. Steamline
18. Mechanical wedging of head against monolith

Figure 3. Prestressed-concrete vessel and its internals for SECURE-P reactor.

leads to the recirculation pump inlet and the other to the upper density lock; the former carrying the main coolant flow and the latter a small flow during normal operation. The density lock is a region where there is open connection to the pool water with mixing prevented by stable thermal stratification and the pressurizer steam volume which is common to all three modules. The recirculation pump pushes the primary coolant through the annular steam generator tube bundle where it is cooled to $260^{\circ} \mathrm{C}$. From the steam generator, the coolant flows further downwards through an annular downcomer to the core inlet plenum which is directly connected to the lower density locks. Here, the hot/cold interface is kept at a desired level by means of control of the recirculation pump speed. In this design, the primary system structures are not exposed to significant pressure differentials and failure of these structures will, in general, lead to mixing of high boron pool water in the circuit causing reactor shut down.

For refuelling, the steel structure housing the upper density locks and module connection to the steam volume is lifted up into the pressurizer volume. Thereupon the closure slab which is an annular structure supporting full reactor pressure in its centre cavity, can be moved sideways for refuelling and service after disconnecting the toroid-type elastic seals between it and the concrete vessel monolith.

The safety performance of the reactor has been studied by theoretical analysis. The 
incidents analysed are the loss of flow, transient overpower and loss of feedwater to the steam generator. The analysis indicates the safe shut down of the reactor without any core damage in all these cases. It is claimed by ASEA/ATOM that the technical feasibility of the reactors is beyond doubt, the concept provides an hitherto unattained level of inherent safety and since PIUS is a modified LWR, the cost of R\&D is small (Hannerz 1987). The spent fuel, being inside the PCRV during operation, is inaccessible for clandestine diversion. However, the stability of interfaces separating the primary coolant from the pool has to be demonstrated, tools and procedures for refuelling and maintaining the reactor efficiently have to be devised, steam generators developed and the overall cost estimated and shown to be competitive.

3.1b The HTG-reactor: The high temperature gas-cooled (HTG) reactor is a heliumcooled and graphite-moderated reactor. The fuel is enriched uranium or a mixture of enriched uranium and thorium, used in the form of carbide and oxide particles individually clad with multilayer ceramic coatings (Gibbons et al 1974). All major components for the primary coolant system, including the steam generators are housed in a steel-lined prestressed concrete reactor vessel (PCRV). The safety in HTGR is achieved through active and passive devices. The main inherent safety characteristics of HTGR are the following (Gibbons et al 1974; Wessman \& Moffette 1974; Arndt et al 1988):

(i) The use of thorium in the fuel element of HTGR results in a large negative and prompt Doppler coefficient of reactivity and hence beneficial effects on selfstabilisation and limitation of reactor power.

(ii) The high heat capacity of the large mass of graphite in the reactor ensures a slow and readily controllable core temperature rise against reactivity and core-cooling transients. The ceramic core (graphite) structure and fuel elements are capable of withstanding high temperatures upto about $3500^{\circ} \mathrm{C}$, hence eliminating the possibility of core meltdown.

(iii) The helium gas used as a coolant has negligible effect on the reactivity of the core. Therefore, the control of the reactor is inherently easier as compared to a reactor where the coolant functions as moderator also.

(iv) The primary coolant system of the reactor is contained within the PCRV. Therefore, the need for external coolant piping that may be postulated to rupture is eliminated. The integrity of the PCRV structure itself precludes the sudden loss of primary coolant. Further, the use of inert helium gas as coolant has the advantage of its being a single-phase fluid. Thus a sudden reduction in primary system pressure can not cause loss of all the coolant or prevent coolant circulation because of change of phase.

The HTGR design is of two types. The West German HTGR concept utilizes a homogeneous pebble-bed core composed of graphite-coated and matrixed spherical fuel elements and the US modular HTGR design utilizes a heterogeneous core composed of a carbonaceous matrix fuel compact inserted into prismatic blocks of graphite (Goodin et al 1988; Kroger \& Schulten 1988). In both the designs, the principal barrier for fission product release is of a generic nature. That is, the coated particle is a microsphere (diameter $0.8 \mathrm{~mm}$ ) consisting of a fuel kernel ( $\mathrm{UO}_{2}$ for West German designs and $\mathrm{UCO}$ or $\mathrm{ThO}_{2}$ for the MHTGR) surrounded by three successive zones of pyrolytic carbon, silicon carbide and pyrolytic carbon. The coating of the HTGR fuel particle is analogous to the containment building of the traditional reactor and has a number of safety advantages like the pressure bearing capability of the SiC coating being approximately 80 times that of a traditional LWR containment, the fission product containment system being distributed over more than $10^{9}$ microspheres rather 
than depending upon only a few barriers, the particle containment performance capable of being continually monitored during normal operation by measuring the primary circuit activity, and fission products being kept at the site of their origin even during off-normal events. Tests under maximum design conditions for passively safe HTGR, with modern high quality FRG-produced fuel, demonstrate with $95 \%$ confidence that fuel failure does not exceed $1 \times 10^{-5}$ during normal operating conditions or $4 \times 10^{-5}$ during off-normal events (Goodin et al 1988).

In the US, the first HTGR which went into commercial operation on the Philadelphia Electric Company System on June 1, 1967, is a $40 \mathrm{MWe}(115 \mathrm{MWth})$ prototype reactor plant (Birely 1974). The other HTGR in US are the 330 MWe Fort St. Vrain Nuclear Generating Station (Habush \& Walker 1974) and a new 2300 MWe Philadelphia Electric Company Project (Gibbons et al 1974). The other HTGR, a $350 \mathrm{MWth}$ modular design with prismatic fuel elements in a side-by-side steel vessel configuration has been developed by General Atomics, Combustion Engineering and Bechtel under the sponsorship of the Department of Energy. Evaluation of this reactor for events like loss of flow, moisture ingress and reactivity insertion, indicated that due to the inherent safety features of HTGR, none of these events would lead to significant fission product release. A typical reactor arrangement is shown in figure 4.

In West Germany, the first pebble-bed HTR with $15 \mathrm{MW}$ power was built in Juliech. It exhibited excellent safety characteristics and operational performance over more than 20 years. The second HTR in West Germany, THTR 300, a 300 MWe nuclear power station went on line on 16 November 1985. The operating experience with THTR 300 has met all expectations and is therefore a reference plant for high temperature reactors in the power range 100 to $600 \mathrm{MWe}$. The HTR-500 nuclear power station, with electrical rating of $500 \mathrm{MWe}$, represents the next step in the process of HTR commercialisation in West Germany. The main design features of this reactor are integrated design of all primary system components in a single cavity concrete pressure vessel, use of standardised components and proven materials from THTR-300 wherever possible, separation of operating and safety systems leading to simple design and accident control by making use of the slow transient characteristics of the high temperature reactor. It has been established by numerous accident and risk analyses that core heat-up due to loss of forced cooling combined with depressurisation of the prestressed concrete reactor vessel would result in the accident having the maximum effect, but that the integrity of PCRV is always maintained. The safety philosophy and characteristics of the HTR module, with its inherent and passive features can withstand any physically possible reactivity insertions with minimum radiological consequences. For HTGR, the risk for low and no rapid or large release of radioactivity to the environment is predicted even for extremely hypothetical events (Simon 1988). For HTGR, an extensive data base is available to understand the fuel performance behaviour. The data have also helped in developing analytical tools to predict conservatively the fuel performance and perform safety analyses.

\subsection{Liquid metal-cooled fast breeder reactor}

In LMFBR, incidents in which power production is more than the power removal of the coolant are known as transient over-power (TOP) and incidents in which power removal becomes less than the normal power production are known as transient under-cooling (TUC) incidents. TUC may occur due to loss of flow (LOF) or loss of heat sink (LOHS). These incidents arising due to mismatch of power production in fission 


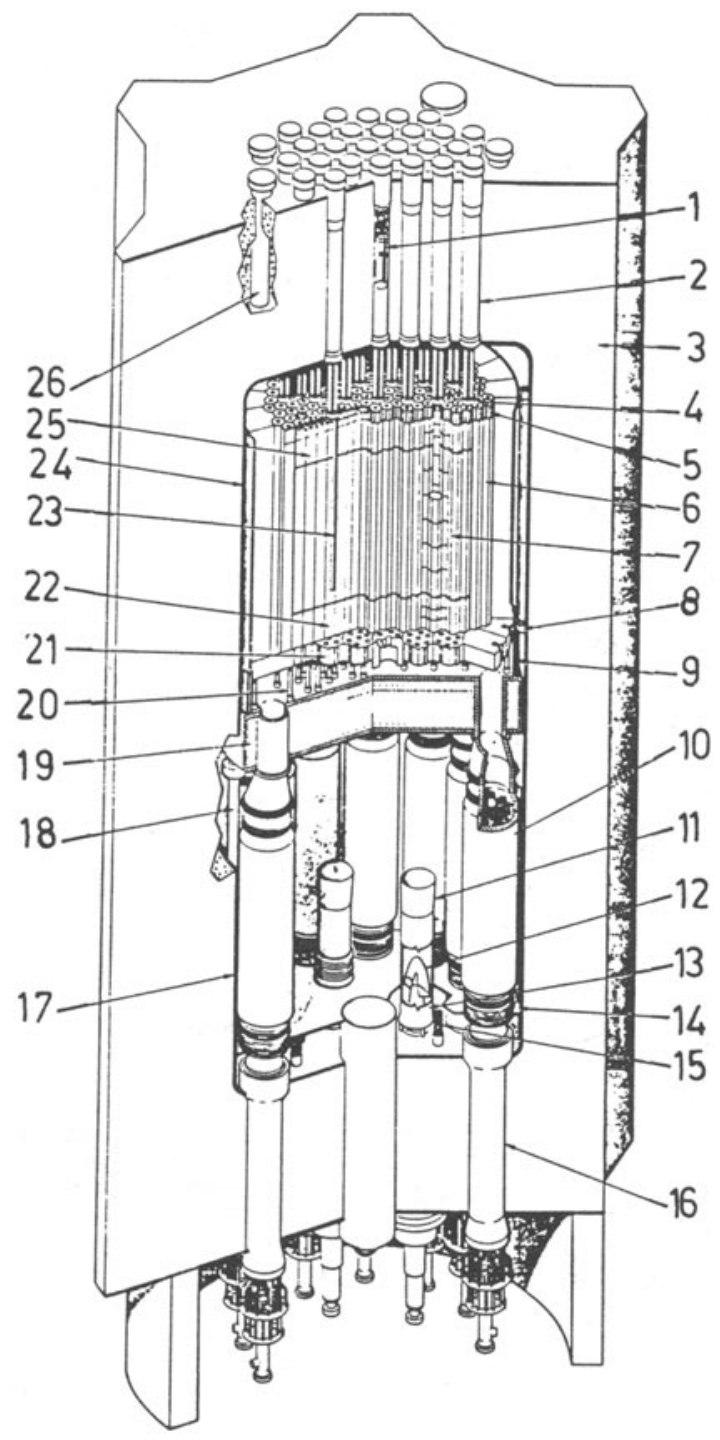

1. Control rod drive

2. Top head penetrations

3. PCRV

4. Orifice valves

5. Top key reflector elements

6. Side reflector

7. Core

8. Core barrel key

9. Core barrel

10. Steam generator modules (12 in number)

11. Circulator diffusers ( 4 in number)

12. Helium valve

13. Circulators (4 in number)

14. Lower floor

15. Flexible columns

16. Bottom head penetrations

17. PCRV liner

18. Core support floor column

19. Support floor

20. Core support posts

21. Core support blocks

22. Bottom reflector

23. Control rod

24. Thermal barrier

25. Top reflector

26. Helium purification system well

Figure 4. HTG reactor arrangement.

and power removal by the coolant are of concern because they may ultimately lead to core-melting and subsequent core disassembly; thus exposing the radioactive core material to the environment. Currently designed LMFBR are of the pool type in which the reactor core, and the entire primary system including the primary pumps and the intermediate heat exchangers are submerged in a big pool of sodium. Hence the concern of safety against loss of coolant does not arise in these reactors. Proper alignment of primary system components, with respect to the core, always leads to setting up of natural convection in the reactor and hence the fission product decay heat can always be removed by this natural process. Therefore, inherent safety in LMFBR demands that in case of TOP, LOF and LOHS, the reactor should come to safe shut down without the use of the plant protection system (PPS). For this, the 
combination of reactivity feedbacks in the system should be such that any temperature rise due to TOP, LOF and LOHS accidents leads to a negative reactivity feedback. In LMFBR the different kinds of reactivity feedbacks available are the following:

3.2a Reactivity feedbacks: (i) Doppler reactivity feedback - This reactivity feedback arises due to the increase in absorption or fission nuclear reactions in the resonance energy range for atoms whose vibrational energy increases due to the temperature rise of the fuel. For small reactors, the neutron spectrum being harder (with more high energy neutrons) and hence the resonance energy neutrons being about 100 times lower than the fission neutron energies, the Doppler coefficient is negligibly small. However, for larger reactors with lower fuel enrichment and smaller neutron leakage, the neutron spectrum is soft (with more lower energy neutrons), so that an appreciable number of neutrons fall in the resonance energy region. Hence the Doppler coefficient is large and negative. The coefficient is largest in oxide-fuelled reactors which have low average neutron energies on account of the presence of two moderating atoms (oxygen) per atom of the fuel. The Doppler coefficient is inversely proportional to the temperature and hence its magnitude decreases with the temperature. In 1972, experiments conducted on SEFOR, an LMFMR of USA (Harris 1973), proved convincingly that a fast power excursion (reactivity insertion upto $\$ 1 \cdot 3$ in $0.1 \mathrm{~s}$ ) can be arrested by the Doppler coefficient.

(ii) Expansion coefficient of reactivity - A rise in temperature leads to decrease in the effective density of core materials. With this all reaction rates decrease and the fraction of neutrons leaking out of the core increases. Both these effects result in negative reactivity for fuel temperature rise. Since there is a gap between the fuel pellet and the clad inner wall, the radial fuel expansion is governed mainly by the radial expansion of the structural material. The time constant of this component depends on the heat transfers involved in heating up the structural material. The fuel pellets' axial expansion is governed by the fuel temperature. It acts fairly fast; the time constant depending on the rate of fuel temperature rise and the time the propagated acoustic wave takes to pass through the fuel element. For small-size reactors, the Doppler coefficient being negligible, the axial and radial fuel expansion coefficients are of great importance. The expansion of sodium and structural material leads to reactivity changes through several opposite effects like gain in reactivity due to the reduction in the absorption of neutrons in these materials and increased fast fission due to hardening of the spectrum resulting from reduced neutron moderation and loss in reactivity due to increased neutron leakage. In smaller sized reactors, the r.utron leakage effect is dominant and so the sodium and structural expansion coefficients lead to loss in reactivity. In large-size reactors, the other two effects (spectral and capture) dominate over the leakage effect and hence the expansion coefficients for coolant and structural material are positive.

(iii) Differential expansion coefficient - On account of the radial temperature gradient in the core, the fuel subassemblies bow radially and there also exists a relative movement between the control rods and core due to temperature difference between the hot sodium on the top in which the control rod shafts dip and the cooler sodium at the bottom around the core support structure. Suitable placing of spacer pads ensures that radial subassembly bowing gives negative reactivity. Control rod shaft expansion always gives negative reactivity. However, the coefficient is not prompt and acts with a time lag that depends on the hot pool heating process. In reactors like the super phenix, this time constant is reported to be in the 10 to 100 seconds range (Gourion et al 1982). 
(iv) Spacer pad expansion - Any temperature transient leading to spacer pad temperature increase may lead to flowering of the core which would give negative reactivity. The time constant of this component depends on the heating rate of the coolant at spacer pad level. While in some reactors this component is definitely finite and negative, in other reactors, say phenix, it is found to be negligible.

(v) Grid plate expansion - Any temperature rise of the grid plate would lead to overall radial core expansion which, in turn, would lead to loss in reactivity. The time constant of this component depends on the mixing and transport of hot coolant from the hot pool of sodium at the subassembly outlet for LOF and from the intermediate heat-exchanger (IHX) for LOHS to the cold pool of sodium at the core inlet. This is of the order of $50 \mathrm{~s}$ in the super phenix reactor (Gourion et al 1982, p. 291).

(vi) Gas expansion module - The gas expansion module (GEM) is essentially a hollow assembly duct which is sealed at the top and open at the bottom. A helium gas bubble trapped inside the assembly expands when the core inlet pressure decreases under LOF and expels sodium from the assembly. The GEM assemblies being placed at the periphery of the core, expulsion of sodium leads to loss in reactivity of the system. GEM assemblies are found to be a very good passive shut-down mechanism in loss of flow cases in the reactor (Cowan et al 1987).

It can be inferred from the above discussion that small-sized reactors have better inherent safety potential because in these reactors all the components of reactivity feedbacks are negative. Large-sized reactors possess positive sodium void coefficients and hence have a lower potential for inherent safety. Further, the relative magnitude of the above reactivity feedbacks is different for different types of fuel, like mixed oxides and carbides of uranium and plutonium, and uranium/plutonium metal. Therefore, the inherent safety potential is also dependent on the type of fuel used in the reactors. We will first discuss the inherent safety potential of different kinds of fuel and then present the inherent safety concepts of LMFBR which have evolved based on the size and the type of fuel used in them.

3.2b Inherent safety potential of different kinds of fuel: The inherent safety potential of oxide, carbide and metal fuel can be judged, particularly against LOHS accidents, simply by assessing whether the coolant inlet temperature rise (of the order of 200 to $250^{\circ} \mathrm{C}$ ) would bring down the power of the reactor. This can be calculated as,

$$
\Delta T_{i}=K_{p} P_{0} / K_{T},
$$

where $\Delta T_{i}$ is the inlet temperature rise of the coolant, $K_{p}$ is the static power coefficient, $K_{T}$ is the isothermal temperature reactivity coefficient and $P_{0}$ is the operating power of the reactor. Equation (1) indicates that the negative reactivity arising from the inlet coolant temperature rise would balance the positive reactivity arising from the power reduction. Table 1 provides $\Delta T_{i}$, calculated for a medium-size reactor of $500 \mathrm{MWe}$ for the three fuels (Singh \& Ponpandi 1986). It can be seen that for metal fuel a small temperature rise is needed to bring down the power of the reactor. Increasingly higher and higher rises in temperature are needed to bring down the power for carbide- and oxide-fuelled reactors. Hence, it appears that it is easier to achieve inherent safety in LMFBR using metal fuel as compared to carbide or oxide fuel. Metal fuel shows better inherent safety potential because of its lower operating temperatures resulting from its higher thermal conductivity. Calculations of $\Delta T_{i}$ for different sizes of the reactors have been reported by Planchon et al (1987). The results are given in table 2. This indicates that the smaller the size of the reactor the better is the potential for inherent safety in LMFBR. 
Table 1. Inlet temperature rise $\left({ }^{\circ} \mathrm{C}\right)$ required to shut down the PFBR

\begin{tabular}{lllll}
\hline & \multicolumn{3}{c}{ Carbide } & \\
\cline { 3 - 4 } Parameter & Oxide & He-bonded & Na-bonded & Metal \\
\hline$K_{p}(\mathrm{pcm} / \mathrm{MW})^{*}$ & -0.77 & -0.56 & -0.30 & -0.15 \\
$K_{t}\left(\mathrm{pcm} /{ }^{\circ} \mathrm{C}\right)$ & -1.08 & -1.07 & -1.07 & -0.81 \\
$\Delta T_{i}\left({ }^{\circ} \mathrm{C}\right)$ & 827 & 611 & 324 & 221 \\
\hline${ }^{*} \mathrm{pcm}=10^{-5}$ & & & & \\
\end{tabular}

With this background we will discuss the inherently safe LMFBR concepts which have evolved in recent years.

3.2c Inherently safe LMFBR: The inherent safety concept developed in LMFBR is based on the modular small reactor concept in which the possibility of core voidage and subsequent core melting in LOF, LOHS and TOP accidents is prevented by inherent negative temperature reactivity feedbacks of the system, and passive decay heat removal is achieved by natural convection processes.

Based on this concept, two reactors have been designed and analysed. The first one is General Electric's PRISM (Power Reactor Inherently Safe Module) and the second one is Rockwell's SAFR (Sodium Advanced Fast Reactor).

(i) PRISM-reactor - The key features of this reactor are depicted in figure 5. It is also based on the modular concept. Each reactor module is a compact $425 \mathrm{MW}$ th pool type, sodium-cooled, breeder reactor design with its own intermediate heat transport system and steam generator system. Steam from three steam generators is fed to a single turbine of $415 \mathrm{MWe}$ capacity. Thus, there are three power blocks and nine modular prism reactors. The reference fuel is a U-Pu- $\mathrm{Zr}$ alloy and the back-up fuel is U-Pu oxide. A unique design feature of the PRISM-reactor is the inherent, passive decay heat removal system termed 'Radiant Vessel Auxiliary Cooling System' (RVACs) (see figure 6). Under normal operating conditions, about $0.2 \%$ power loss occurs from RVACS operation. However, if the intermediate heat transport system fails, radiant heat is transferred from the reactor vessel to the containment vessel where it is removed by the natural circulation of air between the containment vessel and the biological shield.

The prism inherent safety approch has been substantiated by a series of LOF, LOHS and TOP tests conducted on EBR-II (Cowan et al 1987, p. 295). These tests proved that reactivity feedbacks reduce power and maintain codlant temperatures within safety limits. It is discovered that in the case of LoF events, radial core expansion from the core assembly, duct bowing and thermal/mechanical interaction at the upper core

Table 2. Inlet temperature rise $\left({ }^{\circ} \mathrm{C}\right)$ required to shut down the EBR-11 reactor.

\begin{tabular}{lrrrr}
\hline & \multicolumn{4}{c}{ Reactor power (MWth) } \\
\cline { 2 - 5 } Fuel & 20 & 100 & 330 & 1000 \\
\hline Metal & 78 & 184 & 214 & 270 \\
Oxide & - & 628 & 788 & 1012 \\
\hline
\end{tabular}




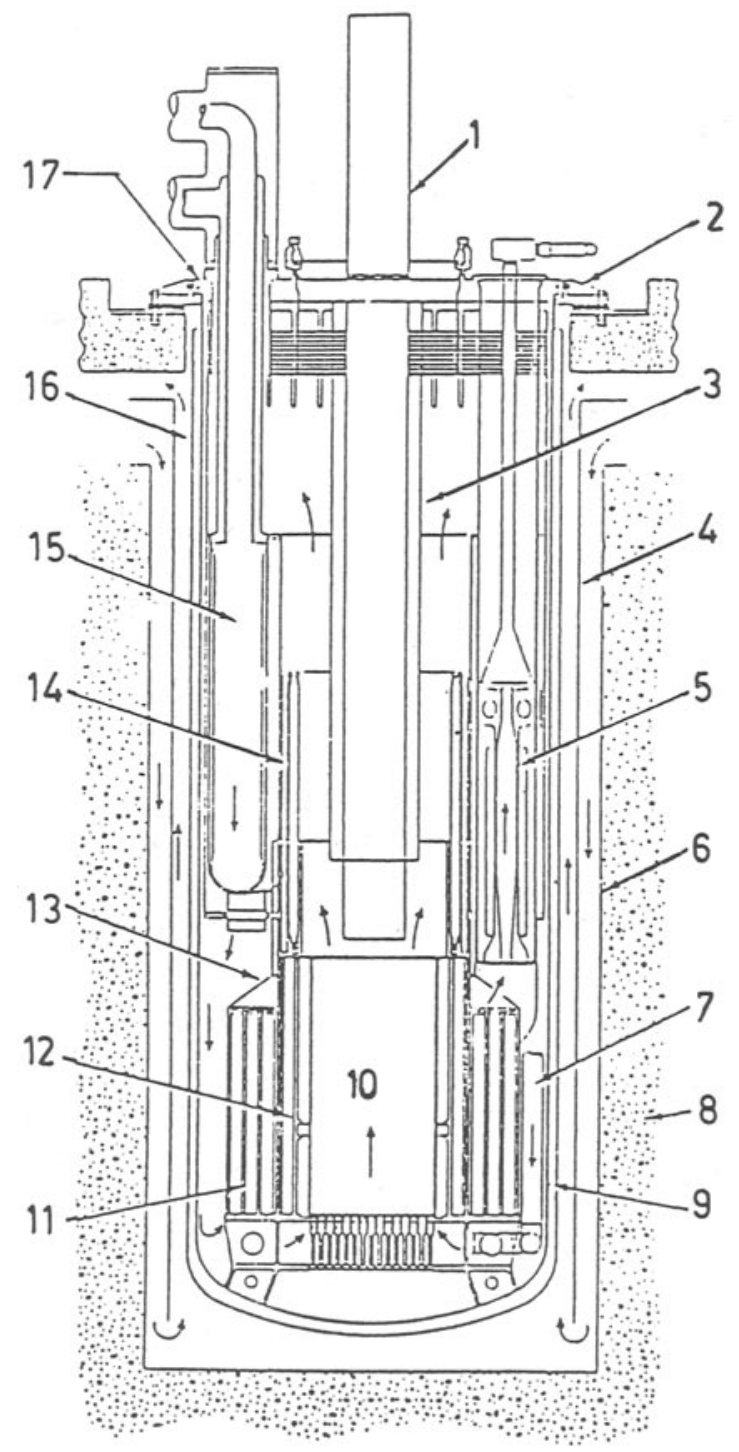

1. Control drive assemblies

2. Reactor support

3. Upper internals

4. Collector cylinder

5. Electromagnetic pump

6. Silo wall

7. Inlet pipe

8. Concrete

9. Reactor vessel

10. Reactor core

11. Fixed shielding

12. Core barrel

13. Support cylinder

14. IHX shields

15. IHX

16. Containment vessel

17. Reactor closure

Figure 5. Key features of the PRISM module.

load pad plane is the main negative feedback for the initial $300 \mathrm{~s}$, and the grid plate expansion thereafter, that inherently shut down the reactor. For LOHS events, grid plate expansion is responsible for inherently safe shut down. For top events, the metal fuel internal conversion ratio is high, hence the individual control rod worth can be kept as low as 35 cents and its withdrawal rate 2 cents/s, thus negative radial expansion of the core is enough to compensate for the positive reactivity arising from control rod withdrawal, and to inherently and safely shut down the reactor. Metal fuel extrusion on temperature rise also leads to large negative reactivity and hence inherently safe shut down.

(ii) The SAFR - This reactor is also based on the modular concept, each reactor module producing $330 \mathrm{MWe}$ and four such reactors producing a total plant power 


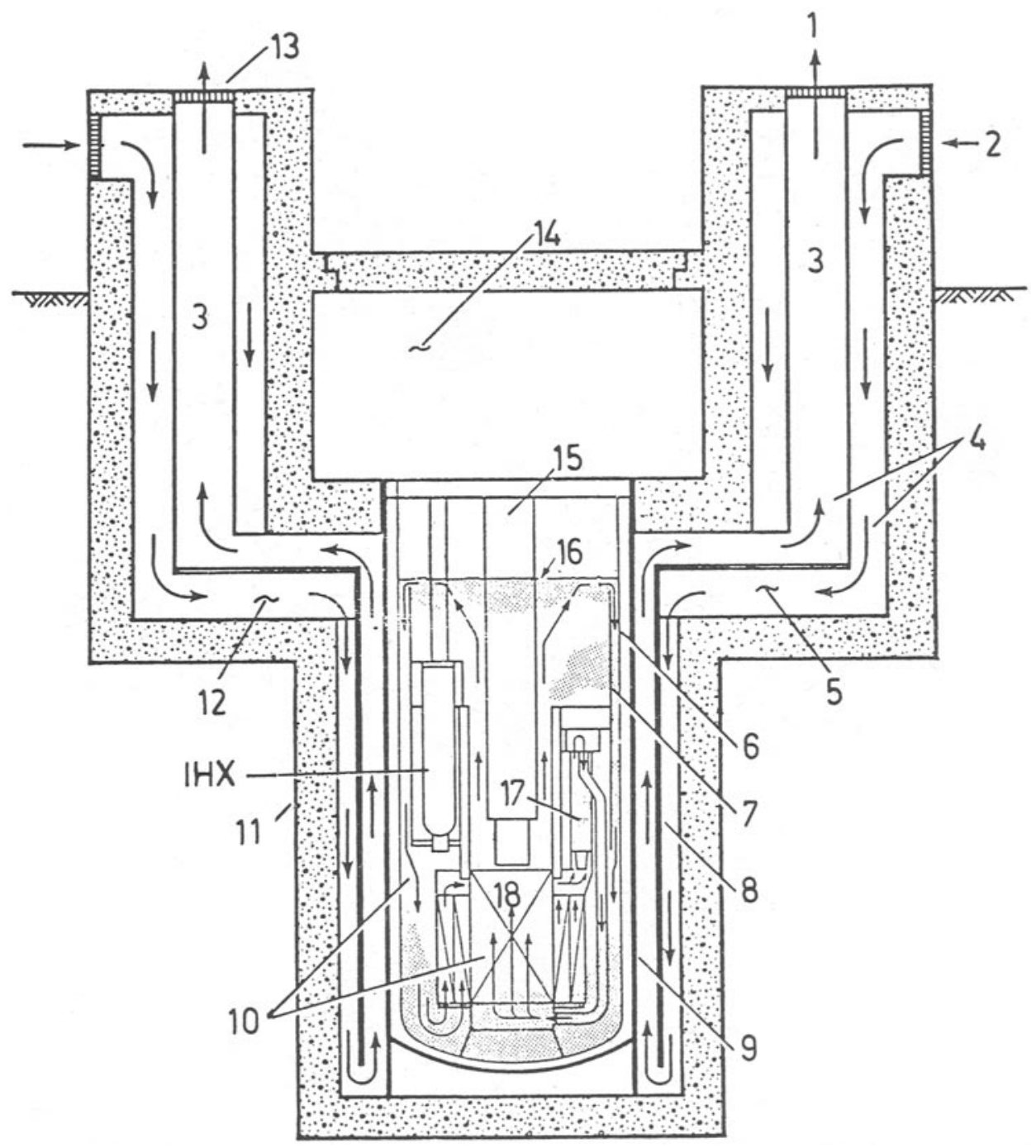

1. Air outlet ( 4 in number)

2. Air inlet (4 in number)

3. Air

4. Air flow path

5. Inlet plenum

6. Reactor vessél

7. Vessel liner

8. Collector cylinder

9. Guard vessel
10. Primary sodium flow path

11. Reactor silo

12. Outlet plenum

13. Grill

14. Head access area

15. Reactor closure

16. Sodium level

17. Pump

18. Core

Figure 6. Primary sodium and RVACS air flow circuit during RVACS operation for heat removal.

of $1320 \mathrm{MWe}$. Fuel used in the reactor could be metal or oxide; metal as reference and oxide as back-up. It is provided with on-site fuel cycle facility for reprocessing the spent fuel. Each reactor is coupled to its own turbine generator. The SAFR reactor module is shown in figure 7. All the primary sodium coolant is contained in the stainless steel reactor vessel and secondary containment is provided by a guard vessal 


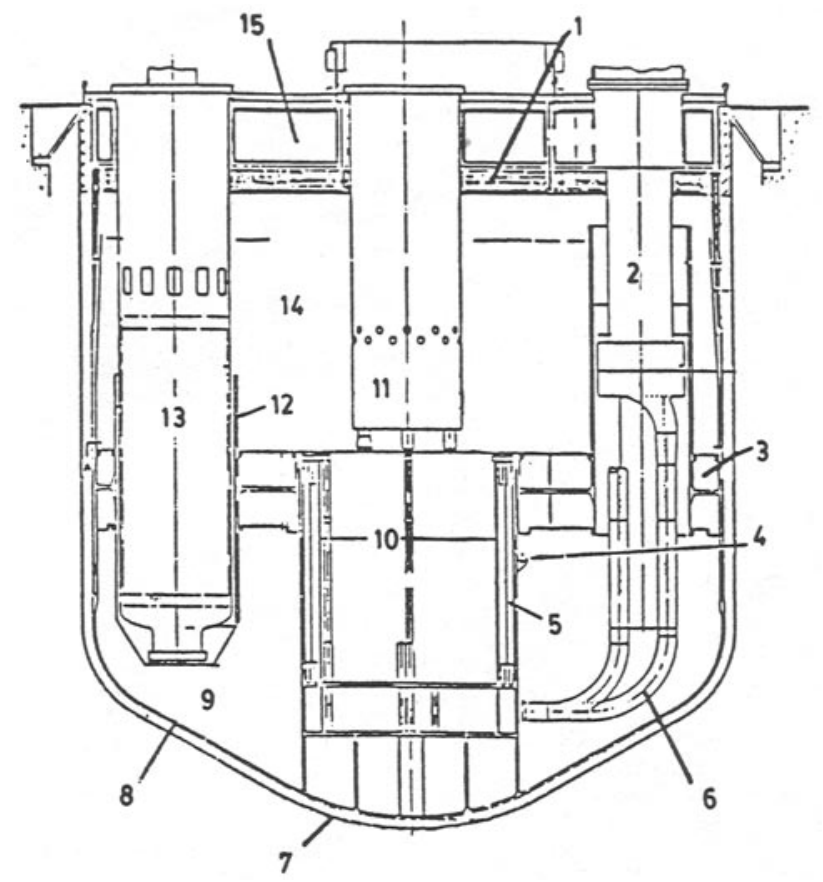

1. Reflective insulation

2. Pump

3. Horizontal redan

4. Neutron detector tube (4 in number)

5. Borated concrete canned shielding

6. Four 14-inch pipes

7. Guard vessel

8. Reactor vessel

9. Cold pool

10. Core

11. Upper internals

12. Borated concrete shielding

13. IHX

14. Hot pool

15. Air-cooled deck

Figure 7. SAFR reactor module.

surrounding the reactor vessel. It can maintain the safe sodium level above the core in the unlikely event of a reactor vessel leak. The guard vessel also provides the containment boundary below the load access area. This allows the reactor air-cooling decay heat removal system, RACS, to operate outside the containment. RACs is one of the two independent systems for shut-down heat removal, the other being the direct reactor auxiliary cooling system, DRACS. Both systems are inherently safe natural convection-cooling systems. The RACs employs passive air-cooling wherein the reactor vessel loses heat by radiation to the guard vessel and the guard vessel is cooled by passing air over it.

The thermal-reactivity response characteristics of the overall assembly are such that it results in safe inherent shut down of the reactor under loss of flow with failure to scram.

\section{Proposed approach for prototype fast breeder reactor}

We have seen that the safety approach in LMFBR is mainly concerned with the design of two safety systems, namely the reactor shut down system and the reactor decay heat removal system. In the design of these systems, two concepts prevail as of today. The first concept or approach relies on purely passive characteristics to survive unprotected accidents through the modular design and the metal fuel. The modular design provides small size (in power and dimensions) to the core and structures. A small unit allows passive decay heat removal (DHR) by using only natural circulation of external air round the reactor module in a specific additional system called Reactor Vessel Auxiliary Cooling System (RVACS), without need of any other system nor even 


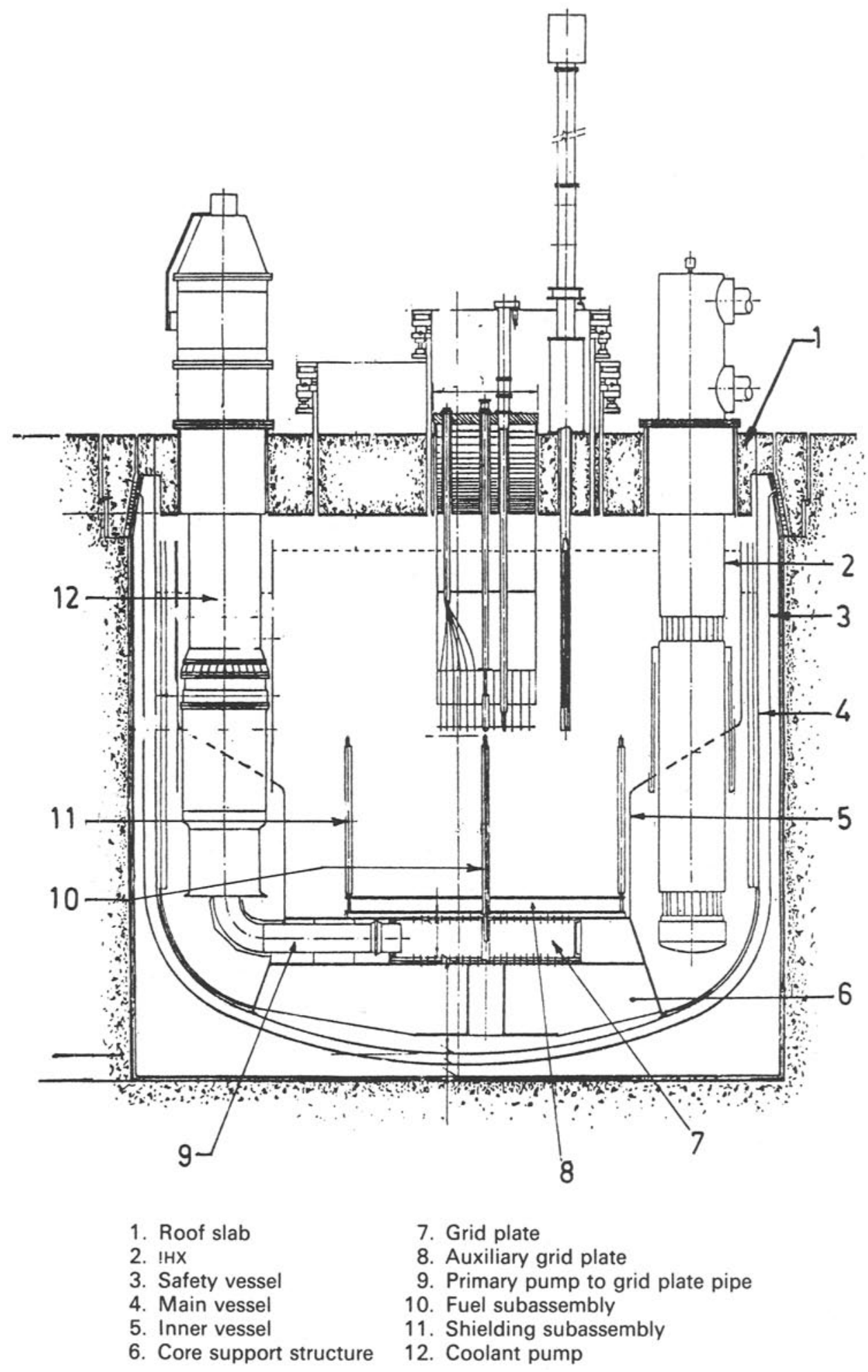

Figure 8. PFBR vertical cross-section. 
active air control dampers. The metal fuel has better potential for bringing down the power of the reactor due to its particular neutronic and thermal characteristics in case of LOF and LOHS accidents. The hard spectrum in metal fuel leads to lower Doppler coefficients and large thermal conductivity leads to low operating temperatures. This combination gives rise to lower positive feedback when fuel temperature decreases in LOF or LOHS accidents. In the case of TOP accidents, metal fuel extrusion during internal heating and low worth of control rods leads to reactor shut down by itself.

The second approach is based on large-size cores and relies more on preventive measures and the use of inherent safety features as well. Preventive measures are made more and more reliable by using the principle of diversity, redundancy etc. in the design of the decay heat-removal system and the reactor shut-down system.

The Prototype Fast Breeder Reactor (PFBR) which is under design at the Indira Gandhi Centre for Atomic Research, Kalpakkam, is a medium size (500 MWe power) sodium-cooled fast reactor. The vertical cross section of the reactor is shown in figure 8. PFBR is a pool-type reactor with core, primary coolant pump, intermediate heat exchanger (IHX), interconnecting piping and grid plate, all located inside a large vessel filled with sodium. The main vessel assembly consists of two concentric vessels. The inner vessel contains reactor core, blanket, radiation shields and a pool of hot sodium at a temperature of $503^{\circ} \mathrm{C}$ and the outer main vessel houses the IHX, pumps and a large volume of cold sodium. The vessel is covered at the top by a roof slab. As the entire primary circuit is contained inside the main vessel there are no pipe penetrations in the main vessel below the sodium level. Secondary sodium inlet and outlet pipes enter the IHX from the top, above the roof slab. The safety design approach for PFBR is to incorporate both the concepts in the design, that is, reliance on preventive measures as well as inherent safety features.

For shutting down the reactor on demand, two independent reactor shut-down systems are to be provided. The rods belonging to the secondary shut-down system are so designed as to be capable of entering the core even when the core is distorted under the action of seismic forces. The rods are known as articulated control rods. Further, the rods of the secondary system will be held by magnets located within the hot pool of the primary sodium such that the overheating of the sodium can itself demagnetise the magnets and result in the drop of the rods into the core. Regarding the removal of decay heat, four separate decay heat-removal systems based on the natural convection of sodium have been provided. The system consists of cooling coils located in the hot primary pool, while the cold end rejects the heat into the atmosphere. With any two of the four circuits in operation, decay heat can be removed without any power being available. The overall power coefficient is negative and grid plate expansion provides large negative feedback. In addition, the possibility of including GEM assemblies are also being studied.

With the above proposed concepts of active and inherent safety, PFBR is expected to be inherently safe.

\section{References}

Arndt E, Roehler E, Schoening J, Wachholz W 1988 Nucl. Eng. Int. 33: 20-28

Birley W C 1974 Nucl. Eng. Design 26: 9-15

Bredolt U, Fredell J, Hannerz K, Kemppainern J, Petersen T, Perid C 1988 Safety of next generation power reactors (Seattle: ANS-Meeting) 
Cowan C L, Dubberley A E, Gluekler E L, Murata R E, Switick D M 1987 Int. Topical Meeting on Advances in Reactor Physics, Mathematics and Computation (Paris: CEC and OECDINEA)

Fisher C, Fortescue P, Goodjohn A J, Olson B E, Silady F A 1984 The safety of the HTGR - an assessment of safety and investment risk, Report GA-C 16928

Gibbons J P, Waage J M, Sieving K W 1974 Nucl. Eng. Design 26: 27-37

Goodin D T, Kania K J, Nabielek H, Schenk W, Verfondern K 1988 ANS Topical Meeting, Safety of next generation power reactors (Seattle: ANS)

Gourion A, Francillon E, Kayser G, Malenfer G, Languielle A 1982 Proc. LMFBR safety topical meeting (Lyon: European Nuclear Society) p. 291

Habush A L, Walker R F 1974 Nucl. Eng. Design 26: 16

Hannerz K 1983 Nucl. Eng. Int. 28: 41-48

Hannerz K 1984 Nucl. Europe 4: 29-33

Hannerz K 1987 Adv. Nucl. Sci. Technol. 19: 41-108

Harris R A 1973 Report HEDL-TME 73-42

Kroger W, Nickel H, Schulten 1988 Nucl. Safety 29: 36-48

Kroger W, Schulten R 1988 ANS Meeting, Safety of Next Generation Power Reactors (Seattle: ANS)

Languielle A 1985 IWGFR/IAEA - Specialists' Meeting on LMFBR Fuel Rod Behaviour under Operational Transients, IAEA Report No. IWGFR-59

Planchon H P, Sackett J I, Golden G H, Sery R H 1987 Nucl. Eng. Design 101: 75-90

Reutler R. Lohnert G H 1983 Nucl. Technol. 62: 22-30

Simon W A 1988 Meeting Summaries of Safety of Next Generation Power Reactors (Seattle: ANs Top Meeting)

Singh O P, Ponpandi S A 1986 Static reactivity coefficients for PFBR oxide, carbide and metallic cores and a preliminary assessment of inherent safety potential of the three systems, Internal Report RG/RPD-291

Walter A E, Reynolds A B 1981 Fast breeder reactors (Pergamon)

Weinberg A M, Spiewak I 1984 Science 224: 1398-1402

Wessman G L, Moffette 1974 Nucl. Eng. Design 26: 78-102 